\title{
Interplay between Type 1 Diabetes Mellitus and Celiac Disease: Implications in Treatment
}

\author{
Navchetan Kaur ${ }^{a}$ Sanjay K. Bhadada ${ }^{b}$ Ranjana W. Minz ${ }^{a}$ Devi Dayal ${ }^{c}$ \\ Rakesh Kochhar $^{\text {d }}$ \\ aDepartment of Immunopathology, Postgraduate Institute of Medical Education and Research, Chandigarh,

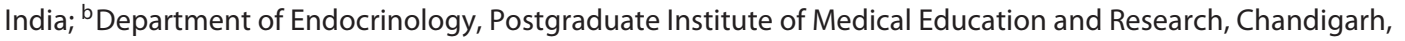 \\ India; ' Department of Pediatrics, Postgraduate Institute of Medical Education and Research, Chandigarh, India; \\ ${ }^{d}$ Department of Gastroenterology, Postgraduate Institute of Medical Education and Research, Chandigarh, India
}

\section{Keywords}

Type 1 diabetes mellitus · Celiac disease · Genetics ·

Coexistence

\section{Abstract}

Background: A complex interplay between genetic and environmental factors contributes to disease etiology of most of the autoimmune disorders. Type 1 diabetes mellitus (T1DM) and celiac disease (CD) are polygenic autoimmune diseases that have high propensity to coexist due to shared etiological factors like genetics and clinico-pathological overlaps. Summary: The mean prevalence rate for coexistence of these diseases is $8 \%$, and this value is a gross underestimation as reported from biopsy-proven symptomatic cases. The prevalence rate will rise when studies will excavate bottom layers of the "celiac iceberg" to detect potential and silent celiac cases. The concomitant presence of both these disorders is a complex situation immunologically as well as clinically. There is an accentuated breakdown of tolerance and proinflammatory cytokine storm that leads to the progression of organ-specific autoimmunity to systemic. No immunomodulating drugs are advocated as exogenous

\section{KARGER}

(c) 2018 S. Karger AG, Basel

E-Mail karger@karger.com

www.karger.com/ddi insulin supplementation and gluten exclusion are recommended for T1DM and CD respectively. Nevertheless, these pose certain challenges to both the clinicians and the patients, as gluten free diet (GFD) has been described to have an impact on glycemic control, bone health, and vascular complications. Also intermittent gluten intake by these patients due to non-compliance with GFD also stimulates the autoreactive immune cells that result in an augmented immune response. Key Messages: Large public health studies are needed to estimate the prevalence of all forms of CD in T1DM patients. Strict global guidelines need to be formulated for the disease management and prognosis, and there is also a need for an extensive research on each front to thoroughly understand the co-occurrence of these diseases.

(c) 2018 S. Karger AG, Basel

\section{Introduction}

Type 1 diabetes mellitus (T1DM) is one of the most common chronic disorders prevalent in young individuals. It is an autoimmune disorder, which is characterized by $\beta$ cell destruction that culminates into absolute insulin 
deficiency resulting in a state of chronic hyperglycemia. The demise of $\beta$ cell is not abrupt; rather it is preceded by a long prodromal phase that can last for about 10 years $[1$, $2]$. This phase is characterized by $\mathrm{CD} 4^{+} \mathrm{CD} 8^{+} \mathrm{T}$ cell infiltration of the pancreatic islets that leads to insulitis, which finally results in apoptosis of $\beta$ cells [3]. In this phase, the patient is asymptomatic but tests positive for serum autoimmune markers for T1DM like anti glutamic acid decarboxylase- 65 autoantibodies (GADA), anti-islet antigen 2 autoantibodies, and insulin autoantibodies $[4,5]$. When only $10-30 \%$ of the islets mass remains, the patients present with symptoms related to hyperglycemia.

The next phase after the clinical onset of the disease is marked by management of elevated blood glucose levels and related complications. Like all autoimmune disorders, T1DM is also a complex genetic disorder in which environmental factors also contribute to the disease etiology. This is evident from the geoepidemiology [6], as the incidences of T1DM have increased by almost twofold in children below the age of 5 . Due to shared genetic components and related environmental factors, the autoimmune diseases tend to cluster in "some" individuals. In T1DM, $10-30 \%$ of the individuals develop other autoimmune diseases and these usually develop after the clinical onset of the disease $[7,8]$. These diseases can be autoimmune thyroid disease (AiTD), celiac disease (CD), uveitis, autoimmune gastritis, vitiligo, and adrenal autoimmunity. The concomitant presence of T1DM with other autoimmune disorders is referred to as autoimmune polyendocrine syndromes (APS). However, this term is a misnomer, as not all autoimmune diseases included in the different categories of APS are endocrine disorders. Nevertheless, 4 categories of APS, which are named as APS- 1 to APS-4, have been described. APS-1, also known as autoimmune polyendocrinopathy candidiasis ectodermal dystrophy is a monogenic disorder that results from mutation in the Aire gene and clinical manifestations include candidiasis, hypoparathyroidism, and Addison's disease. APS-2 is diagnosed when Addison's disease is present along with either T1DM or AiTD. When AiTD is present along with other autoimmune diseases, it is classified as APS-3 and coexistence of T1DM and CD is a subtype of APS- 4 , which $[9,10]$ represents a group that includes combinations not included in the above categories [11].

$\mathrm{CD}$ or non-tropical sprue is also an autoimmune disorder that is characterized by intolerance to wheat gluten. It is marked by both intestinal and extraintestinal manifestations like anemia, delayed puberty, short stature, dermatitis herpetiformis, hypogonadism, and adrenal in- sufficiency $[10,11]$. T1DM patients, who are considered high-risk individuals for CD, usually present this disease in atypical, silent, or potential form [12]. In either of the forms, the presence of CD in T1DM patients can clinically complicate the disease management. Hence, in this review, we have tried to present a comprehensive scenario about the pathological and clinical severity of this APS4 subtype that is emerging to be a more common disorder than expected and has serious implications in disease management and patient care.

\section{Epidemiology}

Walker-Smith first described the coexistence of T1DM-CD in 1969; nonetheless, not much data are available on the prevalence and incidence rates of this APS-4 subtype [13]. The prevalence of CD in T1DM patients is 5-7 times more than the general population. Four to nine percent of the T1DM patients have been described to have $\mathrm{CD}$, compared to the incidence of $1 \%$ in general population [14]. However, this range is much broader as lowest incidence rates of $2.4 \%$ have been described in Finland and highest rate of $16.4 \%$ has been reported from Algeria $[15,16]$. This statistics is also debatable, as Finland has a high prevalence rate of both T1DM $(>40 / 100,000)$ and $\mathrm{CD}(>39 / 100,000)$; therefore, this may just be a gross underestimation, as it comes from a study dated back to 1996 [17]. Recently high frequencies have been reported from populations that have wheat or barley as their staple crop. These include Oran (Algeria) as described above, North India (11.1.\%), and Libya (10.3\%) $[18,19]$. The recent reports from other populations that are not mainly wheat consuming, but also have higher prevalence rate are Saudi Arabia (11.3\%), Denmark (10.4\%), Sweden (9.67\%), Canada (7.7\%), Italy (6.65\%), and Iran (6.2\%) [20-25]. However, comparatively lower rates have been reported from Australia (5.7\%), Tunisia (5.3\%), Austria (5\%), United Kingdom (4.42\%), and Egypt (4\%) [26-30]. These prevalence rates have been illustrated in Figure 1. All these rates have been described for biopsy-proven CD cases, detected on screening of autoantibodies. Hence, these figures represent the classical $\mathrm{CD}$ incidences and lack the estimation of potential or silent forms of CD. The prevalence of CD has been described as a model of an iceberg, where symptomatic cases represent only the visible tip of the iceberg and the asymptomatic cases represent the main chunk of iceberg that is not visible. Thus, it can be speculated that when bottom layers of the "iceberg" are excavated to study the 


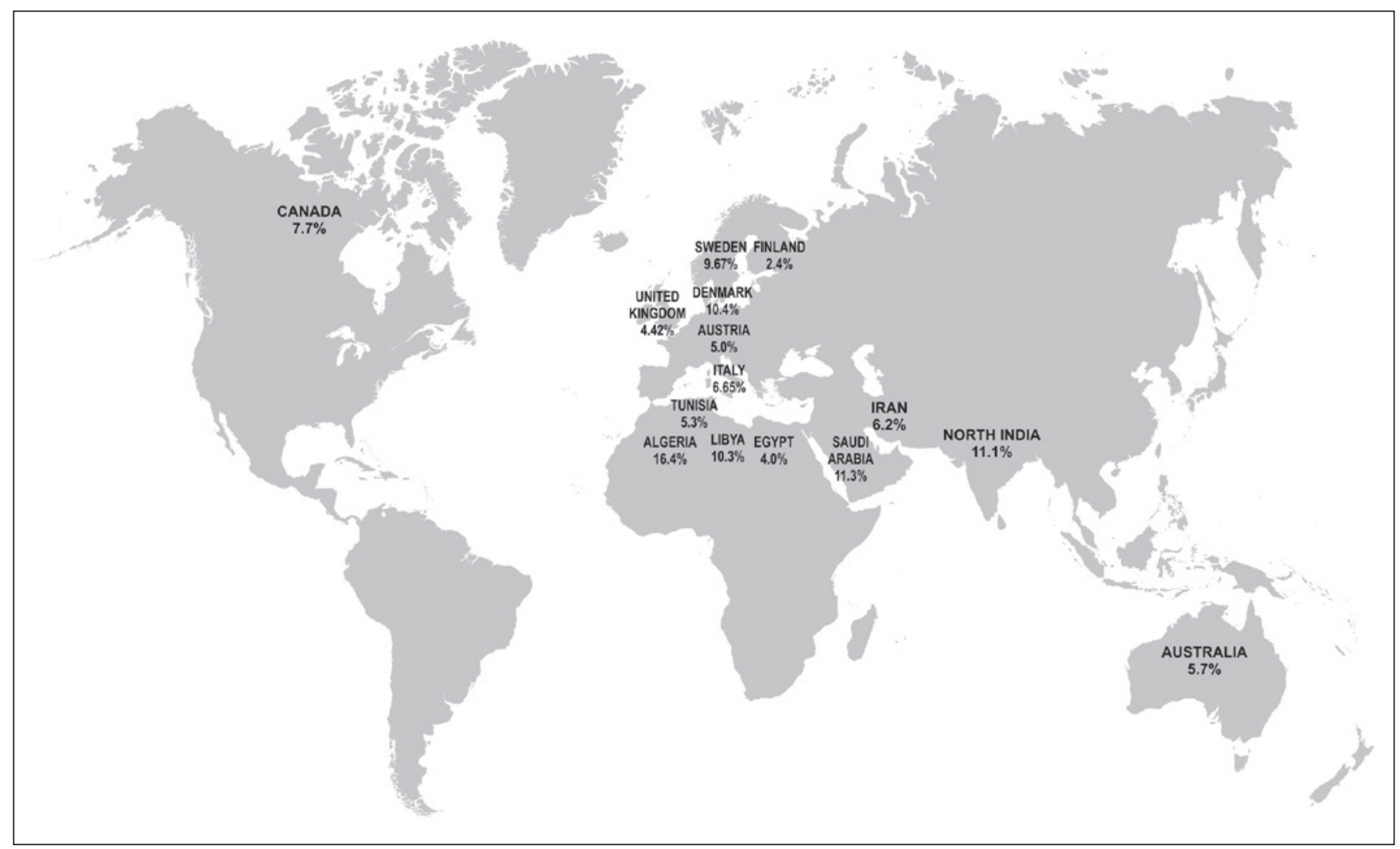

Fig. 1. Described prevalence rates of coexistent type 1 diabetes and celiac disease in different countries and regions.

prevalence of asymptomatic cases, these figures might surge to an alarming level. Comparison of epidemiological parameters of T1DM, CD, and coexistent T1DM and $\mathrm{CD}$ in different geographical regions is shown in Table 1.

\section{Genetic Basis of the Disease}

The molecular basis of both T1DM and CD provides deep insights into the disease mechanisms. Both T1DM and $\mathrm{CD}$ are polygenic disorders, in which more than 30 genetic loci have been described to be associated with the diseases, thereby contributing to the genetic susceptibility. The significance of genetic factors in the etiology of the both T1DM and CD is very well evident from the familial aggregation and concordance rates observed in monozygotic twins. CD is seen in $8-18 \%$ of first-degree relatives and a concordance rate of $70-85 \%$ is seen in monozygotic twins $[31,32]$. In T1DM patients, the rate of familial clustering is $6 \%$ in siblings compared to $0.4 \%$ in US white population and concordance rate of $50 \%$ is seen in monozygotic twins $[33,34]$.

Coexistent Type 1 Diabetes and

Celiac Disease
The role of human leukocyte antigens (HLA) class II genes in the genetic predisposition to both T1DM and CD has been well established. Perhaps, it is this shared genetic susceptibility that might be the major factor leading to the concomitant occurrence of T1DM and CD. HLA class II region that harbors on chromosome $6 \mathrm{p} 21$ comprises 3 loci - DR, DQ, and DP. The high-risk haplotypes for T1DM bank on DR and DQ, that is, DR3-DQA $1 * 0501-\mathrm{DQB} 1{ }^{*} 02$ : 01 and DR4-DQA1*03:01-DQB1*03:02 and account for $30-50 \%$ of T1DM genetic risk [35]. The estimated risk of developing T1DM for the general population in children who have the HLA-DR3/DR4 genotype is approximately 1 in $15-25$ versus 1 in 300 in general population. Furthermore, individuals with high-risk HLA genotypes and at least 2 family members with T1DM have a $50 \%$ of risk of developing T1DM. Also, 33\% of the T1DM patients who are homozygous DR3/DQ2 have anti tissue transglutaminase (tTG) antibodies. Interestingly, the DQB1 alleles contributing to the T1DM risk, that is, $\mathrm{DQB1}{ }^{*} 03: 02$ and $\mathrm{DQB1}{ }^{*} 02: 01$, are also the high-risk alleles for CD. HLA DQ2 is found in $95 \%$ of CD patients and the remaining patients carry DQ8. Patients with refractory CD or enteropa- 
Table 1. Epidemiology of T1DM, CD, and coexistent T1DM and CD

\begin{tabular}{llc}
\hline $\begin{array}{l}\text { Incidence of T1DM } \\
\text { (per 100,000 per year), \% }\end{array}$ & Prevalence of CD, \% & $\begin{array}{l}\text { Prevalence of coexistent } \\
\text { T1DM and CD, \% }\end{array}$ \\
\hline Algeria $4.7[69]$ & North America 0.5-1 [76] & Finland 2.4 [14] \\
Australia 22.6 [70] & Europe 0.5-1 [77] & Algeria 16.4 [15] \\
Canada 39.7 [69, 71] & Ireland 1-1.5 [78] & North India 11.1 [17] \\
China 0.7 [72] & United Kingdom 1-1.5 [78] & Libya 10.3 [18] \\
Iceland 9 [73] & North Africa (Morocco, Algeria, Tunisia, Libya, Egypt) 0.28-5.6 [78] & Denmark 10.4 [19] \\
Israel 5 [69] & Australia 1.2 [78] & Sweden 9.67 [20] \\
Japan 1.7 [69] & Asia 5 [78] & Saudi Arabia 11.3 [21] \\
Libya 8.7 [69] & Middle east 2-8 [78] & Italy 6.65 [22] \\
New Zealand 12.9-23.8 [69, 74] & & Iran 6.2 [23] \\
Peru 0.5 [69] & & Canada 7.7 [24] \\
Thailand 1.65 [75] & & Austria 5 [25] \\
United States 19.4 [69] & & United Kingdom 4.42 [26] \\
& & Egypt 4 [27] \\
& Tunisia 5.3 [28] \\
\end{tabular}

thy associated T-cell lymphoma are often homozygous for DQ2. Both $\alpha$ and $\beta$ heterodimers in cis/trans form, that is, DQ2.5 (DQA1*05:01-DQB1*02:01) or DQ2.2 (DQA1 (02: 01-DQB1*0202, and DQA1*03:01-DQB1*03:02) have been implicated in CD development [36].

DR3 and DQ2 are in strong linkage disequilibrium and therefore, now it is speculated that it is actually the DQ2 molecule that predisposes to T1DM as well, as DQ2 influences the selection and binding of autoantigenic peptide. This is well elucidated for CD, in which negatively charged gliadin peptides as such or modified by tTG bind to DQ2/ DQ8 with high affinity. The lysine position at $\beta 71$ in DQ2 binds to these residues at positions $\mathrm{P} 4, \mathrm{P} 6, \mathrm{P} 7$, and position $\beta 57$ in DQ8 binds at P9 $[37,38]$. However, these mechanisms have not been fully resolved in T1DM, as the triggering factor is not known in the latter case, but it is anticipated that the "diabetogenic peptide" may be binding to DQ2 and DR3 accompanies it due to linkage disequilibrium. It has also been described that the individuals who are homozygous for DQ2.5 or DQ8 have fivefold higher risk for developing T1DM then those who are heterozygous [39].

Since the genetic predisposition conferred by HLA is not absolute; therefore, additional loci might be contributing significantly. Lately, genome wide association studies have identified several single nucleotide polymorphisms that are commonly associated with different autoimmune diseases. These include genes that play a role in T-cell differentiation, survival, migration, or activation like Runt-related transcription factor 3, ETS Proto-Onco-
Table 2. Genetic loci implicated in susceptibility to coexistent T1DM and CD

\begin{tabular}{ll}
\hline Locus/gene & Description \\
\hline DR3-DQ2 & Human leucocyte antigen class II genes \\
DR4-DQ3 & \\
RUNX3 & Runt-related transcription factor 3 \\
ETS2 & ETS Proto-Oncogene 2 \\
FASLG & Fas ligand \\
TNFSF18 & Tumor necrosis factor superfamily member 18 \\
CTLA-4 & Cytotoxic T lymphocyte associate protein 4 \\
ICOS/ICOSLG & Inducible T cell costimulator/ligand \\
CD28 & Costimulatory molecule \\
CD247 & T cell surface glycoprotein \\
SH2B3 & SH2B adaptor family \\
RGS1 & Regulator of G protein Signaling \\
IL18R1 & Interleukin 18 receptor \\
IL1R1 & Interleukin 1 receptor \\
IL1RL2 & Interleukin 1 receptor ligand 2 \\
\hline
\end{tabular}

gene 2, Fas ligand, tumor necrosis factor superfamily member 18, regulator of $G$ protein signaling 1, cytotoxic $\mathrm{T}$ lymphocyte associated protein 4 , ICOS (Inducible T cell costimulator/ligand), CD28, CD247, SH2B3 (SH2 domain containing protein $\mathrm{B}$ adaptor family), and so on. Genes involved in B-cell activation or maturation (ICOSLG, Regulator of G protein Signaling 1) or cytokine genes (IL18R1, IL1R1, IL1RL2) have also been described as the key players. Table 2 shows list of all these genes. However, the association of these single nucleotide poly- 


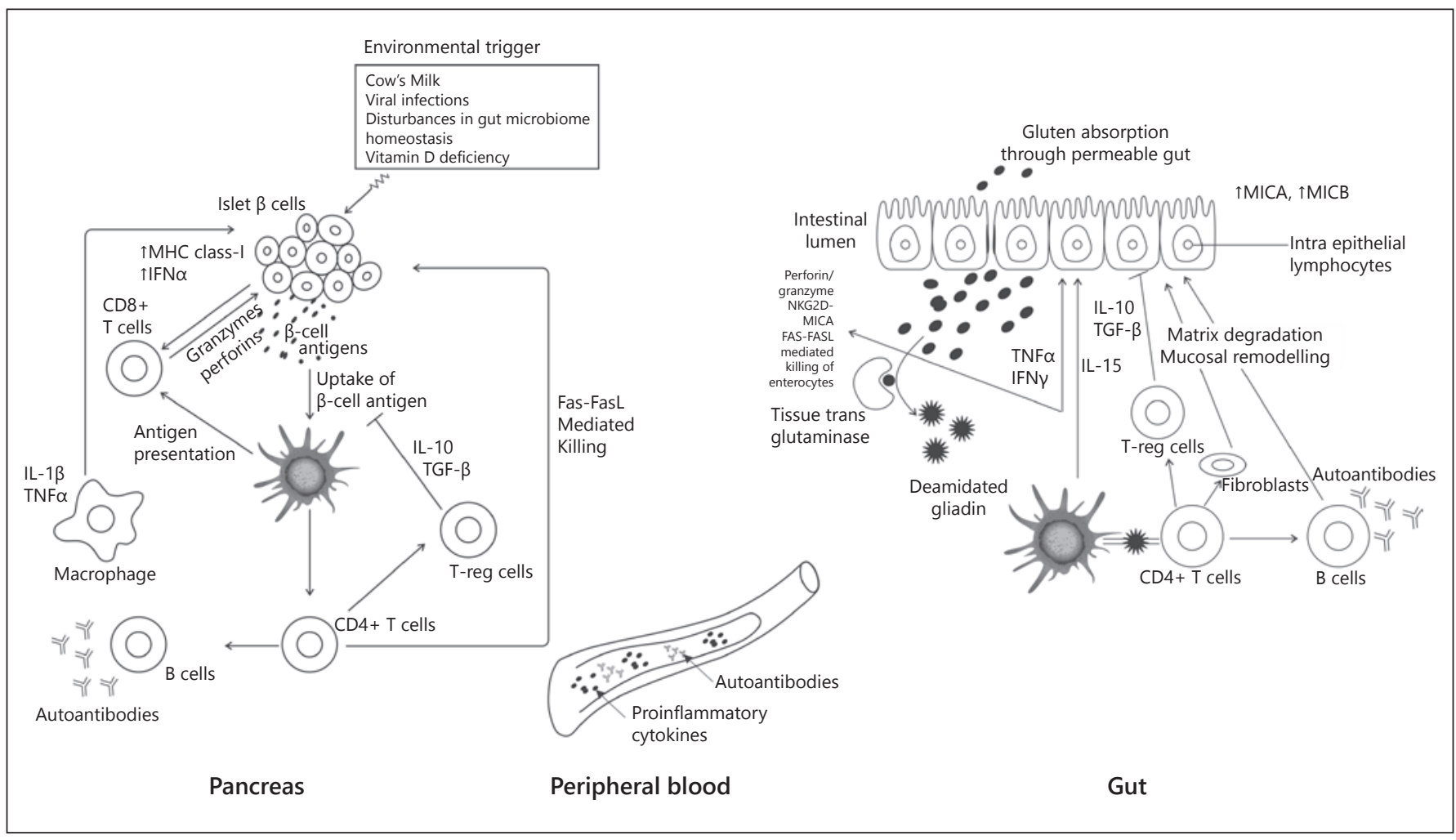

Fig. 2. Pathophysiological mechanisms in type 1 diabetes and celiac disease that lead to immune-mediated killing of $\beta$ cells of islets and enterocytes.

morphisms is weak, compared to the association seen with HLA, as indicated by comparatively lower relative risk and odds ratio. In order to elucidate, the shared loci in T1DM and CD, Smyth et al. [40] have reported that there is considerable overlap in variants, associated with these two conditions. Out of the $8 \mathrm{CD}$ loci, 6 loci showed association with T1DM as well and out of the 17 loci described in T1DM, 8 showed an association with CD. Several of these loci also show an association with other autoimmune diseases.

\section{Pathophysiology}

Both T1DM and CD are marked by the selective destruction of $\beta$ cells of islets and enterocytes respectively. The triggering factor for the cascade of events is not known in T1DM, but the triggering factor is wheat gluten in CD. Because the causing factor in well known in CD, the pathogenic mechanisms of $\mathrm{CD}$ are far more precisely known compared to the mechanisms of T1DM. However, other than gluten, different infectious agents like viruses (adenovirus type 12, hepatitis $\mathrm{C}$ virus, rotavirus) [41] have also been implicated as the risk factors for $\mathrm{CD}$. This is evident from the fact that not all individuals who carry the genetic risk factors develop CD. Similarly, viruses such as enteroviruses and herpesviruses [42] have also been described as the triggering factors for T1DM [43]. Since in most of the cases, T1DM manifests first followed by $\mathrm{CD}$, so here we will try to elucidate the cascade of events in APS-4 subtype in this manner and is shown in Figure 2.

Due to some kind of triggering factor/event, the $\beta$ cells upregulate interferon (IFN)- $\alpha$, and subsequently, major histocompatibility complex (MHC) class I on cell surface. This exposes the $\beta$ cells to attack by the autoreactive $\mathrm{CD}^{+} \mathrm{T}$ cells with specificity for antigens in the pancreas [44]. Type 1 interferons also activate the dendritic cells (DCs) and promote the presentation of $\beta$ cell antigens to T cells. The DCs activate $\mathrm{CD}^{+} \mathrm{T}$ cells, which promote macrophage-mediated killing through the production of cytokines and reactive oxygen species. The $\mathrm{CD} 4^{+} \mathrm{T}$ cells also activate antigen-specific $\mathrm{B}$ cells, which differentiate into antibody-producing plasma 
Table 3. Classical and non-classical symptoms of T1DM and CD

Type 1 diabetes mellitus

Hyperglycemia

Osmotic symptoms-polyuria, polydipsia, polyphagia

Vomiting/abdominal discomfort/constipation/headache

Nocturia, pyogenic skin infections, recurrent candida rash

Urine ketones
Celiac disease

Abdominal discomfort/bloating

Weight loss, fatigue, growth abnormalities

Infertility, hypogonadism

Recurrent aphtous stomatitis

Low bone mineralization

Compensatory hyperthyroidism

Dermatitis herpetiformis

Dental hypoplasia cells. The antibodies bind to $\beta$ cells and $\mathrm{Fc}$ receptors on macrophages and mediate complement killing. The activated B cells can also function as antigen-presenting cells, further enhancing the anti $\beta$ cell immune response. Interaction of $\beta$ cell with antigen-specific $\mathrm{CD} 4^{+} \mathrm{T}$ cells and the presence of proinflammatory cytokines can license the DCs to cross-present antigen to $\beta$ cell antigenspecific $\mathrm{CD}^{+} \mathrm{T}$ cells so that they upregulate their cytotoxic properties. These cytolytic $\mathrm{CD} 8^{+} \mathrm{T}$ cells can kill $\beta$ cells through the release of cytolytic granules containing perforin and granzymes, as well as through apoptotic Fas-FasL cell death pathway. These immune mechanisms can be tempered by regulatory cell subsets such as the IL-4-producing natural killer T cells and forkhead box (Fox) $\mathrm{p}^{+}$regulatory $\mathrm{T}$ (Treg) cells [45]. However, Treg cells can be incapacitated in the presence of certain cytokines, such as IL-21, which release the $\beta$ cell destructive immune response. A remitting relapsing phenomenon results, sometimes with Tregs overpowering the $\mathrm{CD}^{+} \mathrm{T}$-cell-mediated killing of $\beta$ cells. This may be called the "honeymoon phase", where transiently the dependency on insulin is decreased. Eventually T1DM results, when only $10-30 \%$ of the functional $\beta$ cell mass remains [46].

Even after the onset of the disease, immunological remittance is not observed in the patients, as titers of autoantibodies and auto reactive $T$ cell persist for a long duration. It is not known if this is because of the continuous exposure to the "triggering factor" or constant auto antigen exposure. Few of the T1DM patients with long-standing disease or others even with new onset of diabetes develop $\mathrm{CD}$. This is also favored by the dysfunctional state of Tregs and "inflammatory mileu" leading to the persistence of the autoimmune state. Due to immune perturbations and neuropathy induced by hyperglycemia, the gut permeability is affected and the site of the autoimmune reaction now shifts from the pancreas to the gut. It has also been described by researchers that the gut immune system is activated in T1DM patients, as initial priming of diabetogenic cells takes place in the gut and further activation of the immune response takes place in the regional lymph nodes [47].

The pathogenesis of $\mathrm{CD}$ can be divided into 3 phases: luminal and early mucosal events, activation of pathogenic $\mathrm{CD}^{+} \mathrm{T}$ cells, and events leading to tissue damage that involves both innate and adaptive immunity. The pathogenesis of CD is largely attributed to trigger by wheat gluten. "Gluten" refers to the protein complex of wheat that may include more than 100 different molecules. These proteins can be divided on the basis of solubility into gliadins and glutenins [48]. Some incompletely digested peptides of wheat gluten, rye, or barley can cross the epithelium and enter the lamia propria of the small intestine due to increased gut permeability. When gluten is ingested during the first phase, it is digested to form peptides, but due to lack of prolylendopeptidases, the proline- and glutamine-rich residues remain undigested [49]. These glutamine residues can be converted to negatively charged glutamic acids by tTG, which is a calcium-dependent enzyme that mediates deamidation of gliadins that eventually lead to the formation of epitope that binds efficiently to DQ2, which is then recognized by gut $\mathrm{T}$ cells [50]. The peptides generated like the 19 mer trigger an innate immune response that is characterized by the production of IL-15. This affects the epithelial barrier either by increasing the permeability through disruption of tight junctions or by acting on intra epithelial lymphocytes promoting IFN- $\gamma$ production as well as potent cytotoxic activity particularly by natural killer group 2 , member $\mathrm{D}$, natural killer group 2, member $\mathrm{C}$ receptors which recognize (MHC class I chain related antigen A and MHC class I chain related antigen $B$ and HLA-E on epithelial cells), leading to epithelial destruction either by T-cell receptor killing or by cytokine production like IL- 21 and IFN- $\gamma$. 
As a result of increased permeability caused by the events described above, peptides like 33 mer can now reach lamia propria where subsequent binding of these peptides to the HLA molecules results in peptide complexes that can activate host gluten-specific $\mathrm{CD} 4^{+} \mathrm{T}$ cells in lamia propria. These activated $\mathrm{CD} 4^{+} \mathrm{T}$ cells lead to the production of a number of cytokines that can in turn promote inflammation and villous damage in the small intestine through the release of metalloproteinases by fibroblasts and inflammatory cells. Activated gluten-specific $\mathrm{CD}^{+}{ }^{+} \mathrm{T}$ cells can also stimulate $\mathrm{B}$ cell production of antigluten as well as anti-tTG antibodies [51]. It has been shown that the anti-tTG antibodies in CD can interfere with $\mathrm{tTG}$ activity and have a deleterious impact on epithelial cell differentiation $[52,53]$.

There is an emerging evidence that gut microbiome has a strong impact on shaping the autoimmune response in several diseases including T1DM and CD [54]. With many contraindicating reports, it is an ongoing debate whether altered microflora is a causative factor or a consequence of autoimmunity. Priming of autoimmune effector cells takes place in gut in both T1DM and CD. The hypersensitive innate receptors for bacteria and viruses like toll like receptors can trigger an immune response that is autoreactive. Gram-positive bacteria have been shown to be strong inducers of Th1 response [55] leading to proinflammation; furthermore, antibiotic treatment of these bacteria in non-obese diabetic [56] mouse decreases the incidence of T1DM. Children in the prodrome phase show changes in fecal microflora [57]. We have also reported isolation of pathogenic strain of Nesterenkonia jeotgali from duodenal mucosa of CD patient [58]. The exact role of the gut microbiome in pathophysiology is not known currently, but these studies strongly suggest that it modulates the disease mechanism.

\section{Symptomatology, Clinical Presentation, and Diagnosis}

In $90 \%$ of the patients with this APS- 4 subtype, T1DM manifests first followed by CD and in less than $10 \%$ of the patients, other patterns are seen. The exact cause of this manner of disease presentation is not known, but it is speculated that it may be because of the long prodromal phase in which epitope spreading takes place that finally leads to celiac-specific antibodies.

Due to prolonged hyperglycemia, patients present with typical osmotic symptoms like marked weight loss, polyuria, polydipsia, and polyphagia. Besides these spe- cific manifestations, certain nonspecific symptoms also require to be dealt with, to either diagnose or exclude diabetes. These include vomiting, abdominal discomfort, constipation, and headache. Additionally, enuresis in a previously trained child, nocturia, pyogenic skin infections, and recurrent candida rash need consideration for diagnosis/exclusion of T1DM. The presence of urine ketones is also an important marker for diabetes. T1DM patients are generally young, lean, and have a sudden onset of disease and usually the serum c peptide is virtually absent. In the presence of the above-mentioned symptoms, diagnosis of diabetes is done by blood glucose measurements as per American Diabetes Association guidelines [59]. These include random plasma glucose conc $\geq 11.1 \mathrm{mmol} / \mathrm{L}$, fasting plasma glucose conc $\geq 7.0 \mathrm{mmol} / \mathrm{L}$, $2 \mathrm{~h}$ post oral glucose tolerance test $\geq 11.1 \mathrm{mmol} / \mathrm{L}$, and $\mathrm{HbA} 1 \mathrm{c} \geq 6.5 \%$. These patients also have absolute insulin dependency for glycemic control and this is used as a criterion for differentiating T1DM from other forms of diabetes like type 2 diabetes in young, slowly progressive insulin-dependent diabetes mellitus, latent autoimmune diabetes in young as well as latent autoimmune diabetes in adults [60]. About $30 \%$ of the T1DM patients present with hyperglycemic emergencies like diabetic ketoacidosis, but hyperglycemic hyperosmolar state is rarely seen in T1DM patients, though it has a high mortality rate.

At least $90-95 \%$ of the patients with T1DM test positive for either of the autoantibodies at the onset of the diseases. The autoantibodies can be detected against insulin, islet cell antigen, GAD-65, or zinc transporter 8 . Insulin autoantibodies have been implicated as the first antibody to appear in T1DM patients and have been shown to be present years before the onset of the overt diabetes [61]. GADA have been considered the general markers of the autoimmunity and therefore, the correlation of GADA with other disease-specific antibodies such as $\mathrm{CD}$ and AiTD autoantibodies has been described.

Clinical features of CD in T1DM patients may be subtle, atypical, or may be completely lacking. This implies that the T1DM patients may harbor florid CD, silent CD or potential CD. In whatsoever form, detection of CD is crucial in T1DM patients, as inclusion of gluten free diet (GFD) in T1DM patients improves the blood glycemic control, and also has a positive impact on biochemical parameters. Therefore, periodic screening of T1DM patients for $\mathrm{CD}$ is highly recommended. The features that need to be evaluated for CD diagnosis are mild abdominal discomfort and bloating, weight loss, fatigue, growth abnormalities mimicking constitutional growth delay, infertility, recurrent aphtous stomatitis, low bone mineral- 
ization and compensatory hyperthyroidism, and rarely enteropathy-associated T-cell lymphoma. Iron and folic acid deficiency with or without anemia is also one of the most common laboratory findings [62]. T1DM patients with CD have higher propensity for hypoglycemic episodes and are also at increased risk for diabetic retinopathy and nephropathy. The classical and non-classical symptoms of T1DM and CD are summarized in Table 3.

Diagnosis of CD is done by following a protocol that is widely recommended and accepted. It consists of 2 stages that comprise serological testing and histopathological investigation. In the first stage, the patients are screened for autoantibodies anti tTG immunoglobulin A (IgA) and anti EMA (endomysium) IgA. If any patient is detected negative, but is still suspected of $\mathrm{CD}$, then IgA levels are checked for selective IgA deficiency. In case of selective IgA deficiency, tTG IgG and EMA IgG are checked. Other than these 2 antibodies, anti gliadin IgA and IgG as well as anti deamidated gliadin peptide IgA antibodies are also detected in these patients and may be useful in the diagnosis of atypical CD.

If the patient is detected positive for antibodies, then biopsy of small intestine is required to confirm the diagnosis. The characteristic histological changes include an increased no of intraepithelial lymphocytes ( $>25$ per 100 enterocytes), elongation of the crypts, and partial to total villous atrophy [63]. Although there are no strict guidelines formulated by any of the organizations like American Diabetes Association, International Society for Pediatric and Adolescent Diabetes, Canadian Diabetes Association, North American Society of Pediatric Gastroenterology, Hepatology and Nutrition regarding screening of CD in T1DM patients in lieu of controversial reports, periodic screening is recommended irrespective of symptomatic presentation [64].

\section{Treatment and Outcome}

Exogenous insulin supplementation and GFD, which excludes wheat, rye, and barley, are the treatments of choice for T1DM and CD respectively. There is no consensus over the safe limit of gluten that can be included in the daily diet. Henceforth, complete abstinence is recommended. Diet plays a pivotal role in management of both these disorders.

In patients with T1DM, low glycemic index food is recommended; however, dietary options in GFD often have high glycemic index. Therefore, dietary management is complicated when both the diseases coexist. The metabol- ic aspect of these diseases can have influence on several of the associated manifestations as well as on the disease pathogenesis. There are limited numbers of studies that have explored the implications of these treatment regimens on crisscross associated parameters. T1DM patients with undiagnosed or newly diagnosed CD often have poor glycemic control, low total cholesterol, lower high density cholesterol, low diastolic blood, higher prevalence of nephropathy, and retinopathy [65]. These patients often have impaired height, weight, bone mineral density as well body mass index. Few recent studies indicate that these parameters improve within 1 year on compliance with GFD [66, 67]. A study by Cianci et al. [68] shows significant positive impact of GFD on inflammatory immune response.

\section{Future Perspectives}

This review brings out a comprehensive scenario about the coexistence of T1DM and CD. So far the information on the epidemiology, etiology, disease progression and several other aspects of this APS-4s is limited as well as scattered. Though the full understanding of APS-4s is a formidable challenge, insights into the genetic, environmental factors and their functional consequences may serve as an illuminator for multifactorial autoimmune diseases that often coexist. Consistent efforts are needed to search other genetic loci with substantial penetrance power, which may be done by genome wide association studies spanning the intronic regions as well.

Though gluten is the triggering factor for $\mathrm{CD}$, it needs to be found out if there is any common environmental factor for both T1DM and CD that leads to their concurrence. Studies on immunological perturbations to delineate disease pathogenesis would also yield great insights. Finally, we need to study implications of different factors on disease management like the effect of GFD on metabolism, glycemic control, bone health, microvascular complications, and other laboratory derangements. There is also an immediate need for multicentric, collaborative, prospective studies to define algorithms for management of multi-endocrine disorders.

\section{Conclusion}

T1DM and CD coexist in patients more frequently than expected. These patients may present with nonclassical or asymptomatic diseases. Therefore, periodic 
screening of the T1DM patients for CD is highly recommended. The patients often present with additional laboratory derangements and thus necessitate discreet evaluation.

\section{Disclosure Statement}

The authors declare that they have no conflicts of interest to disclose.

\section{References}

1 Devendra D, Liu E, Eisenbarth GS: Type 1 diabetes: recent developments. BMJ 2004;328: 750-754.

2 Akirav E, Kushner JA, Herold KC: Beta-cell mass and type 1 diabetes: going, going, gone? Diabetes 2008;57:2883-2888.

3 Kawasaki E, Abiru N, Eguchi K: Prevention of type 1 diabetes: from the view point of beta cell damage. Diabetes Res Clin Pract 2004; 66(suppl 1):S27-S32.

4 Csorba TR, Lyon AW, Hollenberg MD: Autoimmunity and the pathogenesis of type 1 diabetes. Crit Rev Clin Lab Sci 2010;47:51-71.

5 Taplin CE, Barker JM: Autoantibodies in type 1 diabetes. Autoimmunity 2008;41:11-18.

6 Borchers AT, Uibo R, Gershwin ME: The geoepidemiology of type 1 diabetes. Autoimmun Rev 2010;9.

7 Van den Driessche A, Eenkhoorn V, Van Gaal L, De Block C: Type 1 diabetes and autoimmune polyglandular syndrome: a clinical review. Neth J Med 2009;67:376-387.

8 Husebye ES, Anderson MS: Autoimmune polyendocrine syndromes: clues to type 1 diabetes pathogenesis. Immunity 2010;32:479487.

9 Fasano A, Catassi C: Celiac disease. N Engl J Med 2012;25367:2419-2426.

10 Green PH, Cellier C: Celiac disease. N Engl J Med 2007;357:1731-1743.

11 Betterle C, Zanchetta R: Update on autoimmune polyendocrine syndromes (APS). Acta Biomed 2003;74:9-33.

12 Kumar V, Rajadhyaksha M, Wortsman J: Celiac disease-associated autoimmune endocrinopathies. Clin Vaccine Immunol 2001;8: 678-685.

13 Walker-Smith J, Grigor W: Coeliac disease in a diabetic child. Lancet 1969;293:1021.

14 Camarca ME, Mozzillo E, Nugnes R, Zito E, Falco M, Fattorusso V, et al: Celiac disease in type 1 diabetes mellitus. Ital J Pediatr 2012;38: 10.

15 Denham JM, Hill ID: Celiac disease and autoimmunity: Review and controversies. Curr Allergy Asthma Rep 2013;13:347-353.

16 Saukkonen T, Savilahti E, Reijonen H, Ilonen J, Tuomilehto-Wolf E, Akerblom HK, et al: Coeliac disease: Frequent occurrence after clinical onset of insulin-dependent diabetes mellitus. Childhood diabetes in finland study group. Diabet Med 1996;13:464-470.

17 Boudraa G, Hachelaf W, Benbouabdellah M, Belkadi M, Benmansour FZ, Touhami M: Prevalence of coeliac disease in diabetic children and their first- degree relatives in west
Algeria: screening with serological markers. Acta Paediatr Suppl 1996;85:58-60.

18 Bhadada SK, Kochhar R, Bhansali A, Dutta U, Kumar PR, Poornachandra KS, et al: Prevalence and clinical profile of celiac disease in type 1 diabetes mellitus in north India. J Gastroenterol Hepatol 2011;26:378-381.

19 Ashabani A, Abushofa U, Abusrewill S, Abdelazez M, Tucková L, Tlaskalová-Hogenova $\mathrm{H}$ : The prevalence of coeliac disease in Libyan children with type 1 diabetes mellitus. Diabetes Metab Res Rev 2003;19:69-75.

20 Hansen D, Brock-Jacobsen B, Lund E, Bjørn C, Hansen LP, Nielsen C, et al: Clinical benefit of a gluten-free diet in type 1 diabetic children with screening-detected celiac disease: a population-based screening study with 2 years' follow-up. Diabetes Care 2006;29:2452-2456.

21 Larsson K, Carlsson A, Cederwall E, Jönsson B, Neiderud J, Jonsson B, et al: Annual screening detects celiac disease in children with type 1 diabetes. Pediatr Diabetes 2008;9(4 pt 2): 354-359.

22 Al-Ashwal AA, Shabib SM, Sakati NA, Attia NA: Prevalence and characteristics of celiac disease in type I diabetes mellitus in Saudi Arabia. Saudi Med J 2003;24:1113-1115.

23 Salardi S, Volta U, Zucchini S, Fiorini E, Maltoni G, Vaira B, et al: Prevalence of celiac disease in children with type 1 diabetes mellitus increased in the mid-1990 s: an 18-year longitudinal study based on anti-endomysial antibodies. J Pediatr Gastroenterol Nutr 2008; 46:612-614.

24 Fallahi GH, Ahmadian JH, Rabbani A, Yousefnezhad AS, Rezaei N: Screening for celiac disease in diabetic children from Iran. Indian Pediatr 2010;47:268-270.

25 Gillett PM, Gillett HR, Israel DM, Metzger DL, Stewart L, Chanoine JP, et al: High prevalence of celiac disease in patients with type 1 diabetes detected by antibodies to endomysium and tissue transglutaminase. Can J Gastroenterol 2001;15:297-301.

26 Crone J, Rami B, Huber WD, Granditsch G, Schober E: Prevalence of celiac disease and follow-up of EMA in children and adolescents with type 1 diabetes mellitus. J Pediatr Gastroenterol Nutr 2003;37:67-71.

27 Goh C, Banerjee K: Prevalence of coeliac disease in children and adolescents with type 1 diabetes mellitus in a clinic based population. Postgrad Med J 2007;83:132-136.

28 Salah N, El Hamid FA, Abdelghaffar S, El Sayem M: Prevalence and type of anaemia in young Egyptian patients with type 1 diabetes mellitus. East Mediterr Health J 2005;11:959_ 967.

29 Mankaï A, Ben Hamouda H, Amri F, Ghedira-Besbes L, Harbi A, Tahar Sfar M, et al: Screening by anti-endomysium antibodies for celiac disease in Tunisian children with type 1 diabetes mellitus. Gastroenterol Clin Biol 2007;31:462-466.

30 Smith CM, Clarke CF, Porteous LE, Elsori H, Cameron DJ: Prevalence of coeliac disease and longitudinal follow-up of antigliadin antibody status in children and adolescents with type 1 diabetes mellitus. Pediatr Diabetes 2000;1:199-203.

31 Nisticò L, Fagnani C, Coto I, Percopo S, Cotichini R, Limongelli MG, et al: Concordance, disease progression, and heritability of coeliac disease in Italian twins. Gut 2006;55: 803-804.

32 Corazza G, Valentini RA, Frisoni M, Volta U, Corrao G, Bianchi FB, et al: Gliadin immune reactivity is associated with overt and latent enteropathy in relatives of celiac patients. Gastroenterology 1992;103:1517-1522.

33 Steck AK, Barriga KJ, Emery LM, Fiallo-Scharer RV, Gottlieb PA, Rewers MJ: Secondary attack rate of type 1 diabetes in Colorado families. Diabetes Care 2005;28:296-300.

34 Redondo MJ, Jeffrey J, Fain PR, Eisenbarth GS, Orban T: Concordance for islet autoimmunity among monozygotic twins. N Engl J Med 2008;359:2849-2850.

35 Steck AK, Rewers MJ: Genetics of type 1 diabetes. Clin Chem 2011;57:176-185.

36 Gutierrez-Achury J, Coutinho de Almeida R, Wijmenga C: Shared genetics in coeliac disease and other immune-mediated diseases. J Int Med 2011;269:591-603.

37 Busch R, De Riva A, Hadjinicolaou AV, Jiang W, Hou T, Mellins ED: On the perils of poor editing: regulation of peptide loading by HLA-DQ and H2-A molecules associated with celiac disease and type 1 diabetes. Expert Rev Mol Med 2012;14:e15.

38 Antvorskov JC, Josefsen K, Engkilde K, Funda DP, Buschard K: Dietary gluten and the development of type 1 diabetes. Diabetologia 2014; 57:1770-1780.

39 Di Sabatino A, Vanoli A, Giuffrida P, Luinetti O, Solcia E, Corazza GR: The function of tissue transglutaminase in celiac disease. $\mathrm{Au}$ toimmun Rev 2012;11:746-753.

40 Smyth DJ, Plagnol V, Walker NM, Cooper JD, Downes K, Yang JH, et al: Shared and distinct genetic variants in type 1 diabetes and celiac disease. N Engl J Med 2008;359:2767-2777. 
41 Knip M, Simell O: Environmental triggers of type 1 diabetes. Cold Spring Harb Perspect Biol 2011;3:1-15.

42 Rodriguez-Calvo T, Sabouri S, Anquetil F, von Herrath MG: The viral paradigm in type 1 diabetes: Who are the main suspects? Autoimmun Rev 2016;15:964-969.

43 de Beeck AO, Eizirik DL: Viral infections in type 1 diabetes mellitus - why the $\beta$ cells? Nat Rev Endocrinol 2016;12:263-273.

44 Peakman M: Immunological pathways to $\beta$-cell damage in type 1 diabetes. Diabet Med 2013;30:147-154.

45 Nokoff N, Rewers M: Pathogenesis of type 1 diabetes: Lessons from natural history studies of high-risk individuals. Ann N Y Acad Sci 2013;1281:1-15.

46 Babaya N, Nakayama M, Eisenbarth GS: The stages of type 1A diabetes. Ann N Y Acad Sci 2005;1051:194-204.

47 Jaakkola I, Jalkanen S, Hänninen A: Diabetogenic $\mathrm{T}$ cells are primed both in pancreatic and gut-associated lymph nodes in NOD mice. Eur J Immunol 2003;33:3255-3264.

48 Bernardo D, Garrote JA, Nadal I, León AJ, Calvo C, Fernández-Salazar L, et al: Is it true that coeliacs do not digest gliadin? Degradation pattern of gliadin in coeliac disease small intestinal mucosa. Gut 2009;58:886-887.

49 Barker JM, Liu E: Celiac disease: pathophysiology, clinical manifestations, and associated autoimmune conditions. Adv Pediatr 2008, 55:349-365.

50 Elli L, Roncoroni L, Hils M, Pasternack R, Barisani D, Terrani C, et al: Immunological effects of transglutaminase-treated gluten in coeliac disease. Hum Immunol 2012;73:992997.

51 Schuppan D: Current concepts of celiac disease pathogenesis. Gastroenterology 2000; 119:234-242.

52 Kagnoff MF: Celiac disease: Pathogenesis of a model immunogenetic disease. J Clin Invest 2007;117:41-49.

53 Tjon JM, van Bergen J, Koning F: Celiac disease: how complicated can it get? Immunogenetics 2010;62:641-651.

54 McLean MH, Dieguez D Jr, Miller LM, Young HA: Does the microbiota play a role in the pathogenesis of autoimmune diseases? Gut 2015;64:332-341.

55 Calder PC, Krauss-Etschmann S, de Jong EC, Dupont C, Frick JS, Frokiaer H, et al: Early nutrition and immunity - progress and perspectives. Br J Nutr 2006;96:774-790.

56 Hansen CHF, Krych L, Nielsen DS, Vogensen FK, Hansen LH, Sørensen SJ, et al: Early life treatment with vancomycin propagates Akkermansia muciniphila and reduces diabetes incidence in the NOD mouse. Diabetologia 2012;55:2285-2294.

57 De Goffau MC, Fuentes S, Van Den Bogert B, Honkanen H, De Vos WM, Welling GW, et al: Aberrant gut microbiota composition at the onset of type 1 diabetes in young children. Diabetologia 2014;57:1569-1577.

58 Chander AM, Nair RG, Kaur G, Kochhar R, Dhawan DK, Bhadada SK, et al: Genome insight and comparative pathogenomic analysis of Nesterenkonia jeotgali strain CD08_7 isolated from duodenal mucosa of celiac disease patient. Front Microbiol 2017;8:19.

59 American Diabetes Association AD, Association AD, Li R, Zhang P, Barker L, Chowdhury $F$, et al: Standards of medical care in diabetes 2013. Diabetes Care 2013;36(suppl 1):S11-S66.

60 Canivell S, Gomis R: Diagnosis and classification of autoimmune diabetes mellitus. Autoimmun Rev 2014;13:403-407.

61 Lieberman SM, DiLorenzo TP: A comprehensive guide to antibody and T-cell responses in type 1 diabetes. Tissue Antigens 2003;62:359377.

62 Kakleas K, Karayianni C, Critselis E, Papathanasiou A, Petrou V, Fotinou A, et al: The prevalence and risk factors for coeliac disease among children and adolescents with type 1 diabetes mellitus. Diabetes Res Clin Pract 2010;90:202-208.

63 Marsh MN, Crowe PT: Morphology of the mucosal lesion in gluten sensitivity. Baillieres Clin Gastroenterol 1995;9:273-293.

64 Rostom A, Murray JA, Kagnoff MF: American gastroenterological association (AGA) institute technical review on the diagnosis and management of celiac disease. Gastroenterology 2006;131:1981-2002.

65 Leeds JS, Hopper AD, Hadjivassiliou M, Tesfaye S, Sanders DS: High prevalence of microvascular complications in adults with type 1 diabetes and newly diagnosed celiac disease. Diabetes Care 2011;34:2158-2163.

66 Cohn A, Sofia AM, Kupfer SS: Type 1 diabetes and celiac disease: Clinical overlap and new insights into disease pathogenesis. Curr Diab Rep 2014;14:517.
67 Kaswala D, Veeraraghavan G, Kelly CP, Leffler DA: Celiac disease: diagnostic standards and dilemmas. Diseases 2015;3:86-101.

68 Cianci R, Cammarota G, Frisullo G, Pagliari D, Ianiro G, Martini M, et al: Tissue-infiltrating lymphocytes analysis reveals large modifications of the duodenal "immunological niche" in coeliac disease after gluten-free diet. Clin Transl Gastroenterol 2012;3:e28.

69 Diamond T, Group P: Incidence and trends of childhood Type 1 diabetes worldwide 1990 1999. Diabet Med 2006;23:857-866.

70 Catanzariti L, Faulks K, Moon L, Waters a-M, Flack J, Craig ME: Australia's national trends in the incidence of Type 1 diabetes in 0-14-year-olds, 2000-2006. Diabet Med 2009; 26:596-601.

71 Newhook L, Grant M, Sloka S, Hoque M, Paterson $\mathrm{AD}$, Hagerty $\mathrm{D}$, et al: Very high and increasing incidence of type 1 diabetes mellitus in newfoundland and labrador, Canada. Pediatr Diabetes 2008;9:62-68.

72 Zhang H, Xia W, Yu Q, Wang B, Chen S, Wang $Z$, et al: Increasing incidence of type 1 diabetes in children aged 0-14 years in Harbin, China (1990-2000). Prim Care Diabetes 2008;2:121-126.

73 Helgason T, Danielsen R, Thorsson AV: Incidence and prevalence of Type 1 (insulin-dependent) diabetes mellitus in Icelandic children 1970-1989. Diabetologia 1992;35:880883.

74 Campbell-Stokes PL, Taylor BJ: Prospective incidence study of diabetes mellitus in New Zealand children aged 0 to 14 years. Diabetologia 2005;48:643-648.

75 Tuchinda C, Likitmaskul S, Unachak K, Panamonta O, Patarakijavanich N, Chetthakul T: The epidemiology of type 1 diabetes in Thai children. J Med Assoc Thai 2002;85:648-652.

76 Rubio-Tapia A, Ludvigsson JF, Brantner TL, Murray JA, Everhart JE: The prevalence of celiac disease in the United States. Am J Gastroenterol 2012;107:1538-1544.

77 Mustalahti K, Catassi C, Reunanen A, Fabiani E, Heier M, McMillan S, et al: The prevalence of celiac disease in Europe: Results of a centralized, international mass screening project. Ann Med 2010;42:587-595.

78 Gujral N, Freeman HJ, Thomson AB: Celiac disease: Prevalence, diagnosis, pathogenesis and treatment. World J Gastroenterol 2012; 18:6036-6059. 